\title{
Psychological consequences of war-traumatized children and adolescents in Bosnia and Herzegovina
}

\author{
Mevludin Hasanović ${ }^{1,2}$ \\ ${ }^{1}$ Department of Psychiatry \\ University Clinical Center Tuzla \\ Tuzla, Bosnia and Herzegovina \\ ${ }^{2}$ School of Medicine University of Tuzla \\ Tuzla, Bosnia and Herzegovina
}

Received: 28 February 2011

Accepted: 7 April 2011
Copyright (C) 2011 by Academy of Sciences and Arts of Bosnia and Herzegovina. E-mail for permission to publish: amabih@anubih.ba
Research into the psychosocial consequences of war and political violence on children's and adolescent's developmental wellbeing has shown a steady increase over the last decades. Numerous studies, from differing cultures in different war zones around the world, have documented the effect on children of exposure to war atrocities. The war in Bosnia and Herzegovina (BH) 1992-1995, at the end of $20^{\text {th }}$ century found the citizens of $\mathrm{BH}$ and the world mental health professionals and scientists unprepared to deal with the adverse consequences for the entire $\mathrm{BH}$ population and especially for its most vulnerable part, children and adolescents, to be able to take adequate measures of sufficient mental health care to prevent devastating consequences of severe multiple traumas. Only a few research studies were done during and after this war in $\mathrm{BH}$, the United States, Sweden, Norway, the UK and Germany focusing on the relationship between war trauma, Posttraumatic stress disorder (PTSD), depression, suicidal thoughts, acculturation, repatriation, poverty, behavioral problems, school adjustment, relational problems of children and their mothers after deployment of war PTSD veterans and war prisoners, and treatment of psychological consequences in examined children and adolescents from $\mathrm{BH}$. The major part of this paper reviewed available literature on Medline that reported national and international studies which investigated the psychological consequences of war on $\mathrm{BH}$ children and adolescents and several papers about children and adolescents from Srebrenica, that were not indexed on Medline, but showed very crucial results for the issue described.

Key words: Children, Adolescents, PTSD, Depression, Bosnia and Herzegovina.

\section{Introduction}

The investigation of psychosocial consequences in children and adolescents from living through war and political violence has shown a steady increase over the last decades. Numerous studies, from differing cultures in different war zones around the world, have documented the effect on children of exposure to war atrocities (1). Dur- 
ing the 1992-1995 war in Bosnia and Herzegovina $(\mathrm{BH})$, the whole social structure in the country was destroyed, many families were shattered, and an individual was often left without adequate family and social system support (2). More than two million Bosnian Muslims were ethnically cleansed in the Balkan region; of these, 200,000 were killed while the others were forced to flee their homes and become refugees. This war in $\mathrm{BH}$ has had a tremendous impact on civilians; thousands of inhabitants were left with numerous traumatic experiences (3). Large parts of the population were exposed to extreme threats and intense feelings of helplessness (4). This war has caused a large amount of psychic and social breakdowns. The consequences of the war which caused stress on mental health are of importance, as well as influences on the emotional functioning of individuals caused by changes in the social structure of the population and economic potential of the society (5). After the Dayton Peace Accord was signed in Paris in November 1995 , the war ended the following month. The war in Bosnia lasted approximately 3 and $1 / 2$ years, and although military casualties were high on all sides (6), an estimated 100,000 to 250,000 people were killed and 200,000 were wounded (7), by far the greatest impact of the fighting was on civilians. It is estimated that $>1.3$ million Bosnians were displaced within the country, more than 800000 became refugees to other nations, and up to one quarter of 1 million were killed (6), $90 \%$ of whom were civilian (8). These long-term traumatic and stressful experiences leave an imprint upon people's inner lives and take a long time to heal (4). Children were the most vulnerable. Many of them suffered or witnessed horrifying acts of violence and aggression (4). It is known that massive exposure to wartime trauma overwhelms most psychological defense mechanisms in children, and that children may mitigate war effects in low-to-moder- ately intense wartime settings, which allows effective functioning after acclimatization (9). Although young trauma victims are often resilient, many experience mental health difficulties, including PTSD (4) depression and suicidal thoughts (2). Between 25\%$30 \%$ of Bosnian refugee children lost their fathers in the war in $\mathrm{BH}(4,10)$. Husain et al. (11) reported that two-thirds of $521 \mathrm{Sa}$ rajevo children had lost a member of the family, similar to $52.6 \%-89.6 \%$ of children in our previous studies $(2,4)$. Most children develop strong attachments to their parents (12), which become even stronger in adverse situations. Separation and loss increase the likelihood of various difficulties in children's psychological development. This trauma, in addition to various other types of trauma, explains the high frequency of serious psychological disorders among these children (2).

Whereas there is extensive clinical literature about the developmental challenges facing children and issues of war trauma exposure and postwar adjustment, there is little systematic research about the situation in $\mathrm{BH}$. This review summarizes the findings of the existing publications.

\section{Exposure to war trauma experiences}

The use of violence against civilians in times of war has been one of this century's most alarming military developments, creating increasing numbers of displaced persons and refugees in the wake of regional and tribal conflict. Many refugees were exiled to different European countries, where they faced different acculturation processes (4). 'Loss of place', acute and chronic trauma, family disruption and problems of family reunification have become issues of concern. When BH was thrown into war in 1992-1995, it was clear from the beginning that the extent of the trauma would be enormous and evident for generations to come (13).

The war in $\mathrm{BH}$ was characterized by massive displacement, disruption and loss of life, 
relatives and property. Health and psychosocial well-being were affected in a number of ways. The findings show that there may be more serious longer-term psychological problems in people who are forced to leave their country during wartime (14) even after the war ended. Due to life-threatening danger $\mathrm{BH}$ children and adolescents experienced: "wounding of one's father", "father loss because of killing or missing and loss of immediate or extended family member(s)", "unwillingly leaving home", "separation from family and friends", "forced expulsion from home", "living in collective refugee settlements", "refugee problems and life in a small room in foreign country(ies)". Also, they experienced: "severe fear", shelling and firing very close to children and firing their houses, devastation and ruins" "killing of close relatives and other people", "enemies maltreating father", "running away, hiding and crawling from life threatening danger", "mother's crying and severe sadness", "staying in the concentration camp together with family". Together with their families, during the war in $\mathrm{BH}$ children experienced: "nonadequate residence", "living in collective settlements", "non-adequate and non-safe neighborhood", "separation from parent/s", "poor financial means", "extreme poverty and lack of social support" $(4,14)$. Besides these directly life threatening experiences, children witnessed "dead bodies", "enemy soldiers killing people", "watching people being slaughtered on TV", "wounding and wounded people", "beating and torturing of men and women” (14).

A growing body of research has increased knowledge of the after-effects of trauma in children, including the development of PTSD. Several factors increase children's risk for development of PTSD or PTSD symptoms after trauma. Such information is potentially useful for identifying children who may benefit from more thorough or ongoing assessment after trauma. With regard to as- sessment, an array of increasingly sophisticated and clinically useful measures is being developed; however, currently there is poor high quality data concerning the diagnostic use of different assessments. A significant amount of evidence indicates that trauma can produce diverse reactions in children, including a general increase in internalizing and externalizing symptoms. Clinically useful measuring instruments allow PTSD to be differentiated from this general reaction to traumatic events, much of which may reflect a non-pathological response (15). Selfreport checklists may be useful as a public health measure to assess the prevalence of psychological distress in war affected areas, but they are not an adequate means of clinical screening. Checklists used in combination with other qualitative approaches make it possible to identify those in need and avoid unnecessary pathologization (16). Limited information suggests that PTSD can have a cascading negative effect on children's development and functioning (15). Differences in child exposure during war and exile could be understood in relation to identifiable socio-demographic factors, particularly ethnic background, social class, child age and family size (17). According to most studies, more than half of children exposed to war meet the criteria for PTSD.

Although we know that children are adversely affected by atrocities of war, we do not know which specific war events are associated with children's stress reactions. For example, it is unclear whether differences exist in response to violent versus nonviolent war-trauma experiences (18). Parent and clinician reports show marked group similarities but they often differ with regard to the individual child. Clinician scores reveal a social class gradient not visible on the Harvard Trauma Questionnaire (HTQ) (19, 20). Parent and teenager assessments correlate strongly in total exposure but diverge markedly on specific events. Discrepancy 
derives as frequently from events affirmed by teenagers alone as by parents alone. Primary school children, on the other hand, systematically offer a less-detailed account of their own war exposure. In summary, original HTQ functions "quite well" as a standardized questionnaire, but a Bosnianspecific version would expectedly afford greater validity and capture social class differences in child exposure. For teenagers, the value of multiple informants appears evident; for primary school children, a more adequately age-adjusted procedure remains the first priority (21). Alwood et al. (18) examined the relationship of violent and nonviolent war experiences to children's trauma reactions and adjustment in a group of children from the Bosnian capital, Sarajevo. In their sample of 791 children, $41 \%$ had clinically significant PTSD symptoms. Children were adversely affected by exposure to both violent and nonviolent war-traumas. They found an additive effect of trauma exposure on trauma reactions; however, many war experiences were not associated with the children's adjustment and trauma reactions. They concluded that additive effects of violence and deprivations during war may overwhelm the coping skills of children and leave them vulnerable to externalizing and internalizing adjustment difficulties and symptoms of PTSD (18). Angel et al. (22), in their study of 99 school-aged Bosnian refugee children living in Sweden, who were analyzed to reveal the patterns of war stress experienced and the relationship between these stressors and their current psychological problems, found that when children had experienced much stress, talking about their experiences seemed to exacerbate the negative effects (22).

Papageorgiou et al. (10) found on the Impact of Event Scale (IES) (23) a significant association between the number of war traumatic experiences and the intrusion and avoidance scores (10). Brennen et al. (24) in their study provided evidence that $\mathrm{BH}$ adolescents who were exposed to trauma in childhood have difficulty retrieving specific autobiographical memories (24). To evaluate the psychometric properties of the IES scale in children Dyregrov et al. (25) conducted a study on 1787 children exposed to warfare in Croatia and $\mathrm{BH}$. The study group comprised 877 girls and 910 boys ranging in age from 6 to 15 years. High levels of posttraumatic reactions were found in that group of children. The pattern of endorsement and the factor structure of the IES scale were similar to that found in other samples. As in other studies, both the overall IES score as well as the intrusion and avoidance score were significantly higher in girls than boys. The factor structure for boys and girls were very similar, and the reliability of the scale was adequate across different age groups and for subgroups of displaced and refugee children (25).

In the BH war 1992-95, the citizens of Sarajevo and Srebrenica were exposed to extremely severe war trauma. There are only a few studies that have researched the psychosocial consequences on war traumatized children and adolescents from these two places.

\section{Sarajevo}

The Siege of Sarajevo was the longest siege of a capital city in the history of modern warfare (26). The capital city of $\mathrm{BH}$ was besieged from April 5, 1992 to February 29, 1996 during the $\mathrm{BH}$ war, with a siege force of 18,000 stationed in the surrounding hills, from which Serb soldiers assaulted the city with weapons that included artillery, mortars, tanks, anti-aircraft guns, heavy machineguns, multiple rocket launchers, rocketlaunched aircraft bombs, and sniper rifles (27). From May 2, 1992, the Serbs blockaded the city. The defense forces of the $\mathrm{BH}$ government inside the besieged city were poor- 
ly equipped and unable to break the siege. It is estimated that nearly 10,000 people were killed or went missing in the city, including over 1,500 children. An additional 56,000 people were wounded, including nearly 15,000 children. The 1991 census indicates that before the siege the city and its surrounding areas had a population of 525,980 . There are estimates that prior to the siege the population in the city proper were 435,000 . The current estimates of the number of persons living in Sarajevo range between 300,000 and 380,000 residents (28). Among the children and adolescents there was an increase in neurotic and psychotic disorders in the very beginning of the first year of the war, and a decrease in the same diagnoses during the second year. This might be explained by the particular adaptation of the youngsters to the war conditions. When we are talking about the invalidity of neurological and psychiatric disorders, the investigations showed that illness is the mostly caused by invalidity ( $85.1 \%$ ) among the global invalidity during the war in Sarajevo (5). The effect of long-standing siege on children is less researched because of the rare occurrence of siege conditions these days and the difficulties those conditions present for research. Husain et al. (11) did a unique study in that the participants lived in prolonged siege conditions and were deprived of the basic necessities of life for over 1 year. They were exposed to random sniper fire from the hills surrounding the city of Sarajevo, and many lost family members and close friends. In the completely unusual circumstances that the siege of Sarajevo presented at the time of the study, data were collected in February and March 1994 from 791 children studied, aged 7-15 years; the mean age was 11.0 years $(\mathrm{SD}=2.3)$ in one school district. They could not determine how their sample differed from children in other school districts in Sarajevo. Data on socioeconomic status were not included because of the widespread deprivation resulting from the war. Of 719 subjects, eighty-five percent of the samples had experienced sniper fire, but there was no significant relationship between experiencing sniper fire and the development of PTSD symptoms. A total of 521 (66\%) of the children had lost a member of their immediate or extended family; children who had experienced such a loss had more symptoms of PTSD. Twenty-six percent of our sample experienced food deprivation, $48 \%$ experienced clothing deprivation, $29 \%$ reported shortage of water, and 10\% reported lack of shelter. The children who experienced lack of water and shelter were significantly more likely to manifest avoidance and reexperiencing symptoms than those who did not. Girls reported significantly higher mean scores for avoidance cluster, Impact of Event Scale, and cluster of re-experiencing symptoms than boys. The loss of a family member and deprivation of food, water, and shelter had a severe adverse impact on the children. They identified the needs for food and clothing more frequently than the needs for water and shelter. In general, deprivation was associated with significantly increased symptoms of avoidance and hyper-vigilance. Results of this study imply that proximity to war atrocities and personal losses are highly correlated with the development of symptoms of PTSD (11). To examine risk and protective factors of postwar adjustment among adolescents from Sarajevo who had been exposed to war traumas during the war in Bosnia and Herzegovina DurakovićBelko et al. (2003) specifically examined differential linkages between PTSD symptoms and depression (as outcomes) and (a) war traumas, (b) individual and socio-environmental factors, and (c) cognitive appraisals and coping mechanisms. Their results of hierarchical multiple regression analyses indicated that the dimensions of war traumas, individual characteristics, and cognitive appraisals and coping mechanisms play a sig- 
nificant role in determining who will have more serious PTSD symptoms. Although individual and socio-environmental factors are the strongest predictors of depression, the dimensions of war traumas are also significantly correlated with depressive symptoms. Common risk factors for more serious depression and PTSD symptoms in postwar adjustment were female gender and low optimism. While the strongest predictor of posttraumatic stress reactions (PTSR) was trauma experience in the category of loss, the strongest predictor of depressive symptoms was female gender (29). In their conceptualized an overview of the clinically verified psychological consequences of warstress exposure in children and adolescents in BH, Daneš and Horvat (30) presented data that related to the city of Sarajevo, as their sample was in a particular way very specific in comparison with other areas of $\mathrm{BH}$. They found that all types of stressors affecting the population could be found there, and had particular significance in the light of the status of the city of Sarajevo as a war target. The delivered data were presented as a comparison of the clinical phenomena during the war and those several years afterwards. It was evident from the data that the war has left psychological consequences in the developing population, primarily in quantitative terms, i.e., in the increase of prevalence of psychological disorders by approximately $15 \%$ compared to the pre-war circumstances (30).

\section{Srebrenica}

During the recent $\mathrm{BH}$ war, Srebrenica was a United Nations safe haven, but besieged citizens suffered because of a systematic blockade of relief convoys which disrupted access to many foodstuffs (31). Many children, more than 1,000 between October 1992 and May 1993, died there from hunger and disease (32). Children in Srebrenica lived in a horrible environment and each of them was physically and psychologically abused and terrorized by the various disastrous war events. Tahirović (33) found in his study that all children from Srebrenica have had high IES scores and a high degree of distress, consequently this study showed that young children who had suffered the horror of war presented suboptimal growth (33). The darkest moment in the international involvement in Bosnia was the fall of the Bosniak-populated, eastern Bosnian enclave of Srebrenica on July $11^{\text {th }}, 1995$. It became a significant event that fundamentally changed the conflict dynamics and enhanced the prospect for peace (7). On that day about 15,000 people attempted to walk from the enclave of Srebrenica to free territory in Bosnia. Two-thirds were captured or killed. Many of the remainder experienced hallucinations on the march, leading them to believe they were the victims of chemical weapons. After the literature on the likeliest $\mathrm{CW}$ agent, 3-quinuclidinyl benzilate (BZ), and on stress as a cause of hallucinations was reviewed, CW exposure could not be ruled out. It was concluded that the hallucinations can be ascribed to the consequence of multiple stress: artillery attacks, exhaustion due to lack of sleep, starvation, thirst and the effects of drinking unpurified water (34). Despite the fact that Srebrenica was a United Nations (UN) safe zone, the murder of 7,000-8,000 Bosniak men was not prevented. Some were killed after surrendering, believing the UN would protect them. Others were hunted down while attempting to escape into Bosnian government-held territory. Some committed suicide, unable to endure the harrowing trek to safe ground (7). Hasanović et al. $(14,36)$ in their study, analyzed acculturation and psychological characteristics of Bosnian refugee and internally displaced adolescents who survived the Bosnian war and the Srebrenica enclave disaster. All of them survived a very difficult 
humanitarian disaster, being besieged without a normal life together with the threat of war they were exposed to together with their families. After separation from the men, adolescents who participated in this study reported that they were transported in crowded trucks and buses together with their mothers, very old men and other children to Dubrave airport close to Tuzla town. Among the more than 15, 000 displaced persons arriving from the Srebrenica enclave, the field emergency services found various pathologies in these exhausted persons. Among children there was a predominance of cases of respiratory disease and untreated skin infections (35). As Srebrenica is one of five regions of $\mathrm{BH}$ previously identified as iodine deficient, continual prophylaxis was realized with iodized salt over the twenty years prior to the war in the former Yugoslavia. Thus, Tahirović et al. (31) investigated the current state of iodine nutrition in Srebrenica children who had undergone the siege, and found that urinary iodine concentrations were significantly lower than those for controls from Tuzla. The obvious cause was the interruption of the availability of iodized salt by the blockade of relief convoys while Srebrenica was a United Nations safe haven (31). During the research $(14,36)$ in May 1999, some of the adolescents were in the process of repatriation to their home country after a certain period of life in exile (1995-1998), and others from the investigated group stayed during and after the war in $\mathrm{BH}$ as internally displaced persons, without the possibility of returning to their place of origin despite the end of the war. Adolescents from Srebrenica were compared with their peers from Janja and Bijeljina (Semberija plain), who survived different catastrophic war conditions at the very beginning; and some were exiled (1992-1998) and some were internally displaced, but did not go through the Srebrenica disaster $(14,36)$. This study showed that in both groups, par- ticipants who had been internally displaced or/and refugee adolescents had been exposed to severe war trauma and had reported high levels of traumatization more than three years after the war. The prevalence and severity of trauma experiences were significantly related to their region of residence, with adolescents from the region of Srebrenica having a significantly higher prevalence and severity of experiences. We found that adolescents from Srebrenica, after surviving the initial war experiences in 1992, stayed in their homeland significantly more and survived additional trauma exposure to war catastrophes as internally displaced persons in the so called "free territory", while a significantly lower number of adolescents from the same region were exiled from $\mathrm{BH}$ during and after the war, compared with their peers from Semberija. Being forcedly expelled from private property and homes, $56.6 \%$ of Srebrenica participants were resettled as displaced or exiled persons in collective settlements significantly more than those from Semberija. Srebrenica participants survived significantly more war related catastrophic experiences, while participants from Semberija reported significantly more frequently trauma experiences related to the process of exile and repatriation. In the Srebrenica group the severity of traumatic experiences was not related to age and gender, but was related to refugee status and father loss. The internally displaced and those who lost their father reported significantly more severe trauma experiences. In the Semberija group, the severity of trauma experiences did not relate to refugee status or father loss. Being out of the war did not help exiled adolescents to diminish the severity of many trauma experiences. Girls and older participants had significantly more severe trauma experiences similar to other studies $(2,4,11,14)$.

Amongst 143 participants from the Srebrenica region $36.4 \%$ experienced loss of their father which is significantly more than 
those from Semberija, IDP experienced the loss of their father much more than refugees; also, $89.4 \%$ of 143 Srebrenica adolescents experienced separation from family and friends, which is significantly more than their peers from Semberija. Adolescents from Srebrenica were significantly less active, less sociable, in other words they were more introverted $(14,36)$. Psychological trauma, physical injury and low socioeconomic status provoked by the events of war delayed menarchal age among girls who survived the Srebrenica disaster (37).

\section{Acculturation}

As stated previously, together with adults, many children witnessed or experienced traumatic events, and many families were forced to leave their homes. Many found refuge in European countries, where they faced different acculturation processes (4). There are only two studies that have investigated the acculturation problems of $\mathrm{BH}$ refuges $(4,14)$.

Hasanović et al. (4) found returnees reported significantly fewer acculturation problems, such as: "thought about native place after arriving in refugee/displaced environment," "wanted to return to homeland/hometown," "was sad after arriving in refugee/displaced environment," "listened to news from homeland/hometown," "had digestion problems after being exiled/displaced," and "missed friends during exile/ displacement". Younger returnees significantly more often "thought about hometown after arriving in a foreign country" than older ones. Older non-repatriated adolescents had "digestion problems in displacement" significantly more often than younger ones. Older returnees and older internally displaced pupils "were forbidden to play outside" significantly more than younger ones. Internally displaced girls were significantly more often "sad after arriving in the place of displacement" than boys. Re- patriated girls were significantly more often "forbidden to play outside in place of exile" than boys. Repatriated boys were "prevented from accepting the new environment" significantly more often than girls. Internally displaced girls were significantly more often prevented from accepting their new environment (milieu) than boys. Returnees who had lost their father were significantly more often "Sad after arriving in the place of exile" than those who had both parents. They experienced "sleeping disturbances" more often than those who had complete families. Internally displaced adolescents in $\mathrm{BH}$ who had lost their fathers had significantly more "sleeping disturbances" and "digestion problems" than those with both parents. On the other hand, returnees who had both parents "were forbidden to play outside" significantly more often than those who had lost a father. Internally displaced adolescents who had lost a father wanted to "return to homeland" significantly more often than those who had both parents. During exile, returnees who lost their father "listened to news from their home country" significantly more often than their peers who did not lose their father (4). In the other study regarding acculturation problems, participants from Srebrenica reported significantly more that they: "missed friends during exile/displacement", "wanted to return to native place/ homeland", "listened to news from hometown/homeland" and "had digestion problems after being exiled/displaced". Acculturation problems were highly correlated with occurrence of school-emotional/behavioral problems $(14,36)$.

\section{Repatriation}

In 1995, after the end of the war in Bosnia, a number of refugee families were repatriated, often against their whish, and returned to a completely changed, unsafe, and devastated environment. During this process, children 
were exposed to further stress caused by dislocation and the process of acculturation. This has left long-term emotional scars and mental health problems, including PTSD, in children and the adolescent population. In the study of Hasanović et al. (4) on 120 refuge adolescents who returned to their homeland, but not to their own prewar property, after return to their home country, $79 \%$ returnees had no social support; $58 \%$ of them had unemployed parents; $10 \%$ were living in extreme poverty and only $10.8 \%$ had properly resolved health care insurance. For $87 \%$ of returnees, the school system was completely different than in the exile country, and for $77 \%$ their economic situation was worse than in exile, $73 \%$ preferred watching exile country programs on satellite TV, and $48 \%$ were sad after return. Older returnees reported significantly more often "a different school system in home country than in country of exile". They also reported significantly more "missing being with their old friends," whereas younger returnees reported significantly more "communication problems with friends, relatives and neighbors" and "digestion difficulties". Returnee girls reported significantly more "a different school system in the home country than in the country of exile," and "missing being with old friends," whereas returnee boys reported difficulties with school studies more often after their return. Returnees who had both parents, reported significantly more "worsening of economic situation than before exile" and "missing being with old friends," whereas returnees who had lost their father reported significantly more "difficulties with teacher/s" (4). In the study about Srebrenica and Semberija adolescents $(14,36)$ according to difficulties experienced during repatriation, Semberija students reported significantly more: "economic situation is worse than before the exile", "preferring to watch programs from exile country on satellite TV" and "missed meeting with friends from pre-war period". In both groups the participant were "sad after return" $45-48 \%$ with no significant difference between the groups. Returnees from the Srebrenica group who "listened to news from their home country" and who "missed friends in exile" had more "sleeping difficulties" after return to their home country. Those who "were thinking about relatives" in exile were more sad in their home country and had more "sleeping disturbances" after return. Those returnees who preferred to "watch exile country programs on satellite TV" in home country, had less "thinking about native place in exile". Semberija returnees who preferred to "watch exile country programs on satellite TV" in home country, had less sadness during exile, less "sleeping difficulties" in exile, less "digestive problems", they "missed friend(s) from home country" less during exile, wanted to "return to home country" less and "listened to news from home country" less during exile. Adolescents who stayed in their home country during the whole war and postwar period were faced with different acculturation processes in the new environments but in the same culture and their mother tongue. They, together with other family members remained exposed to continual life-threatening situations, sometimes very often. They had more problems to adapt to their new life environment than those who were in exile, probably because they experienced more discomfort and life threatening conditions in the war zone of their own homeland $(14,36)$. The process of acculturation after returning to one's home country is a long-lasting and very complex process in view of all the emotional, socio-political and financial obstacles they had to face and go through with minimal harm. The findings of this survey of Bosnia-Herzegovina internally displaced and refugee adolescents living in post war conditions after surviving fighting, expulsion from home, displace- 
ment, exile, acculturation, repatriation, loss of fathers, loss of close family members, loss of property, lack of safety and normal conditions for life suggest that today and in the future the impact of the war was both severe and widespread $(14,36)$.

\section{Post-traumatic stress disorder}

As part of a United Nations Children's Fund (UNICEF) psychosocial program during the war in $\mathrm{BH}$, data were collected from a community sample of 2,976 children aged between 9 and 14 years. Children completed standardized self-report measures of posttraumatic stress symptoms, depression, anxiety, and grief, as well as a report of the amount of their own exposure to war-related violence. Results showed that children reported high levels of posttraumatic stress symptoms and grief reactions. However, their self-reported levels of depression and anxiety were not raised. Levels of distress were related to children's amount and type of exposure. Girls reported more distress than boys, but there were few meaningful age effects within the age band studied (37).

According to previously established cut-off scores on self-report measures, in a sample of 95 children of 8-13 years, who had experienced the war in Bosnia 65 (28\%), scored within the clinical range on the IES measuring PTSD reactions (11). The level severity of re-experience cluster symptoms, were significantly higher among adolescents from Srebrenica. The prevalence of PTSD in the Srebrenica group $(67.8 \%)$ was significantly higher than $52.4 \%$ in the Semberija group of respondents. PTSD prevalence was higher in both groups than in other studies $(14,35)$. Eytan et al. in their study about Albanian Kosovar found out 23.5\% PTSD prevalence (38), but it was less than $94 \%$ in 364 IDP children from central Bosnia in the study of Goldstein et al. (6). In the study on 186 children/adolescents (2) PTSD was present in $51.6 \%$ of them, with the highest prevalence among children in the non-governmental Children's Village. PTSD prevalence was higher among children who lost a parent but lived with the surviving parent than among children in the governmental orphanage or children living with both parents. Loss of a parent was associated with higher frequency of PTSD. The loss of both parents was associated with high prevalence of PTSD. Prevalence of PTSD was positively correlated with the prevalence of depression. The children/adolescents who survived war traumas but were living with both parents reported the lowest rate of psychological disturbances (2). In the study of IDP and returnees (4) the whole sample, 149 (62\%) of 239 adolescents reported symptoms that met DSM-IV criteria for PTSD; the repatriated group had 57\% of 120 and non-repatriated group had $68 \%$ of 119 participants with PTSD. The prevalence of PTSD was significantly greater among older returnees than among younger ones. PTSD prevalence among younger returnee boys was significantly higher than among their girl peers, whereas PTSD prevalence among older returnee girls was significantly higher than among boys. Internally displaced adolescent girls had significantly greater prevalence of PTSD than boys. Father loss had no substantial influence on the prevalence of PTSD among returnees, either in the whole group or in age subgroups. However, more internally displaced adolescents who had lost their father had PTSD both in the whole group, and in age subgroups (4). Hasanović et al. (29) in their study about adolescents from rural (Teočak) and urban (Tuzla) settings found that adolescents experienced an extremely high number of traumatic events, as described elsewhere $(2,4)$. Of 366 tested adolescents, $40.4 \%$ reported symptoms that met PTSD criteria. Adolescents from the rural area demonstrated PTSD significantly more frequently $53.9 \%$ than their urban 
peers $25.4 \%$. We found that significant predictor variables for development of PTSD symptoms were rural settings, being female, actual lack of money in family, experiences of coldness and lack of food during the war. The prevalence of PTSD was higher amongst adolescents from the rural areas. In rural areas age and gender did not influence the prevalence of PTSD, but in urban areas girls and older participants presented significantly more frequently with PTSD. Adolescents who experienced forced expulsion from their homes, home destruction, shelling, firing, and killing of close family member(s) reported significantly more PTSD. Adolescents who developed PTSD expressed a higher level of desire not to be born in $\mathrm{BH}$ and a lack of prospects in $\mathrm{BH}$ (39). Furthermore, rural adolescents had significantly higher scores on individual PTSD items. Adolescents who grow up in vulnerable families may have different difficulties $(2,4,9)$. In this study we found that between $28-62 \%$ of adolescents lost close family member(s) in the 1992-1995 war in $\mathrm{BH}$. This was similar to previous studies about $\mathrm{BH}$ children and adolescents (2, $4,10,11,14,39)$. In this study, in the rural area, more than half the adolescents lost close family member(s). This one event, in association with other reported traumas, may explain such a high frequency of serious psychological disorders among rural adolescents. It is possible that these children continue to live in vulnerable families whose members have not yet finished the mourning process $(2,10,11,40)$.

\section{Depression and suicidal thoughts}

There are only a few studies that have investigated depressiveness and suicidal thoughts in the period after the $\mathrm{BH}$ war amongst children and adolescents who experienced war. One of these was the study of Papageorgiou et al. (2000), who according to previously established cut-off scores on self-report measures, found 45 children (47\%) scored within the clinical range on the Depression Self-Rating Scale for Children in a sample of 95 children of 8-13 years, who had experienced the war in Bosnia (10).

Among orphan children and adolescents in the study of Hasanović et al. (11) all participants experienced war trauma, many had psychological consequences, and depression was presented in 42 of 186 (22.6\%) children, but with no statistical difference among the groups. The prevalence of depression was similar in boys and girls. Loss of a parent was associated with a higher frequency of depression. The loss of both parents was not associated with a high prevalence of depression. The highest prevalence of depression, often comorbid with PTSD, was found among children who lost one or both parents. The children with the lowest rate of psychological disturbances were those living with both parents (2). In the study about rural and urban adolescents, the rural group had statistically more depression symptoms than their peers from the urban region.

68 of $366(18.6 \%)$ tested adolescents met the Children's Depression Inventory (CDI) criteria for depression. There was no difference between rural and urban adolescents in the frequency of depression. The number of adolescents who reported suicidal thoughts but would not commit suicide was higher in the rural group (40.9\%) than in the urban group (27.8\%). Amongst those who would kill themselves there was no difference (15.0\%) in rural and (15.6\%) in urban areas.

Forcible expulsion from home, home destruction, separation from family longer than three weeks, lack of money for everyday needs, worse financial situation than before the war and extreme poverty increased the prevalence of depression. Those who developed depression expressed a desire not to be born in $\mathrm{BH}$ and an opinion of having no prospects in $\mathrm{BH}$. There was a positive as- 
sociation between age, frequency of trauma experiences, PTSD, depression, hopelessness, and suicidal thoughts (40). In the study about Srebrenica/Semberija adolescents, we found significantly more severe anxious/depressed behavior, withdrawn/depressed behavior, and significantly more severe internalizing problems in the Srebrenica group. They had significantly more severe thought problems and attention problems. In the Srebrenica group IDP adolescents had more anxious/depressed behavior, withdrawn/depressed behavior and internalizing behavior than refuges. Girls were more withdrawn/ depressed than boys. In the Srebrenica group, participants who met new friends had somatic complaints, those who continued education with their peers had less anxious/ depressed behavior. Participants who had "learning difficulties" after return had withdrawal/depression problems, but reported more somatic complaints $(14,36,38)$.

\section{Behavioral problems}

In their study, Hasanović et al. (14) found that in the Srebrenica group IDP adolescents had more social problems, thought problems, attention problems, "other problems" and "everything listed - total problems" compared with refugees. Girls had more thought problems, while boys had more aggressive behavior. Older Srebrenica participants had more of all the school behavioral problems, except attention problems, aggressive behavior and externalizing behavior than younger participants. Participants who lost fathers had more attention problems, but externalizing problems than those who had both parents. Participants who developed PTSD had more thought problems and had less aggressive behavior. Participants who smoke cigarettes had more attention problems. Participants with withdrawn/depressed behavior, somatic complains, internalizing behavior, social problems, thought problems, at- tention problems and with "total problems" misused illicit drugs more than those who did not have contact with it. Semberija participants smoked cigarettes more than Srebrenica ones. Srebrenica participants who lost fathers misuse illicit drugs, smoke cigarettes and drink alcohol more than those who have both parents. Among Srebrenica adolescents those who reported "sleeping disturbances, alimentary problems, prevented from playing outside in the refugee environment and acceptance of new environment" reported the most school/behavioral problems reported by school teachers. Only "listening to news from homeland" highly negatively correlated with the aggressive behavior of these participants. Those who had trouble with teachers had more social and "other problems" $(14,36)$. With the hypothesis that school bullying was more frequent in Stolac than in Posušje, due to the greater level of aggression in children caused by recent war events Cerni Obrdalj and Rumboldt (2008) compared the prevalence and characteristics of bullying between these two towns in BH: Stolac, which was exposed to firearm conflict and Posušje, which was outside the active combat zone during the 1992-1995 war in BH. They found that every sixth pupil (16.4\%) experienced at least one form of bullying almost every day, while 34 (7.0\%) pupils constantly bullied other children. Sixth-eighth graders were more often bullies than 4 th-5th graders. Girls were most often victims of bullying, while boys were most often bullies. The expected difference in bullying between the two towns was not observed, except for older pupils in Posušje, who were more violent than their peers in Stolac. Among the analyzed variables of sex, age, town, and school achievement, only male sex was a significant predictor of bullying, increasing the relative risk by 3,005 times. They concluded that bullying among primary school pupils did not differ between areas that experienced war activities in 1992 - 
1995 (41). Their results differed in relation to the results of a study conducted in Croatia, which showed that primary school children from a town exposed to war perceived themselves as more aggressive in their early adolescence than their peers from a town that was not exposed to war (42). Zalihić et al. (43) reported that children of fathers who had PTSD, experienced stomach pain, eating problems and breathing problems more often than children of fathers who did not have PTSD. Children of fathers with PTSD were more easily upset and worried more often; they were also more aggressive towards other children. The group of children of no PTSD fathers who wanted to help with the house work was larger than the group of children whose father(s) had PTSD (43).

\section{Military and concentration camp related PTSD in war veterans and war prisoners and family relationships}

Almost all children and adolescents and their families experienced different numerous personal trauma experiences and the stress of the deployment of a family member(s) during the recent 1992-1995 war in BH. Some veterans developed posttraumatic stress disorder as a consequence of their experiences. This condition drives many of the adverse changes in the families of returning veterans, through the effects on intimacy and nurturance in their families of withdrawal, numbing and irritability that are components of PTSD. War related PTSD, as well as the intimate relationship problems that accompany the disorder, can influence the course of veterans' trauma recovery. This became the targeted interest of research. The association between PTSD and intimate relationship problems confirmed (44). The surviving family members may have war-related PTSD and depression, thus are unable to create a protective atmosphere for the child's development (2).
It is known that the children of depressed parents are at higher risk of psychopathology $(2,45)$. Zalihić et al. (43) analyzed the frequency of depression and anxiety and children's behavior in families where the head of the family (father) suffered from military related PTSD, in participants living in Mostar. They found that a significantly larger number of women, whose husbands had PTSD, were depressed, unlike women whose husbands were not ill. There was no significant difference in depression manifestation in a group of children older than 18 , as well as in the behavior of a group of children younger than 18 , but significant differences were found in some answers provided, that indicate differences between the noPTSD and PTSD groups (42). Among 209 displaced women attending a Women's Center in a war zone in $\mathrm{BH}$ in 1994, who had survived the most severe traumas (concentration camps or other kinds of detention) the proportion of PTSD cases was highest: $71 \%$ compared to $47 \%$ of the women without this kind of traumatic background. High numbers of traumas, having children, being over 25 years of age, and the reporting of an absent husband, were characteristics associated with being a PTSD-case. In the multivariate analysis, severe trauma and reporting of an absent husband remained significantly associated with PTSD-cases (46). In terms of the satisfaction of children in BH whose parents suffered from PTSD, there was a distinction in contacts with their families, relatives, schoolmates and formal contacts. For children of parents who have symptoms of PTSD, the most important persons that they communicate with were schoolmates and they had problems communicating with fathers and males $(47,48)$. There is the more general challenge that all families and children face when a partner/ parent deploys of role ambiguity consequent on anxiety that is provoked by the threat that deployed family members experience. 
A study of Kuwaiti military showed that mothers' anxiety had the greatest impact on the children of deployed fathers, although absence of posttraumatic stress disorder in mothers could mitigate the effects of their fathers' posttraumatic stress disorder (49). As part of a UNICEF-sponsored Psychosocial Program in Bosnia, data were collected from a representative sample of 339 children aged 9-14 years, their mothers and teachers in order to investigate risk and moderating factors in children's psychological reactions to war. Self-reported data from children revealed high levels of post-traumatic stress symptoms and grief reactions, but normal levels of depression and anxiety. The mothers' self-reports also indicated high levels of post-traumatic stress reactions, but normal levels of depression and anxiety. Child distress was related to both their level of exposure and to maternal reactions. There is also a substantive association between maternal mental health and children's adjustment following the war (50).

Prevalence rates are also likely to be affected by issues related to the course of PTSD, chronicity, and comorbidity; symptom overlap with other psychiatric disorders; and sociopolitical and cultural factors that may vary over time and by nation. The disorder represents a significant and costly illness to veterans, their families, and society as a whole (51). Green et al. (52) evaluated the association of resilience and trauma exposure with the main effects of PTSD revealed from combat exposure, lifetime trauma exposure, and resilience. They found a significant interaction between combat exposure and resilience in that higher levels of resilience were particularly protective among individuals with high combat exposure. After controlling for age, gender, minority status, trauma exposure and PTSD diagnosis, resilience was uniquely associated with decreased suicidality, reduced alcohol problems, lower depressive symptom se- verity, and fewer current health complaints and lifetime and past-year medical problems. These results suggest that resilience is a construct that may play a unique role in the occurrence of PTSD and the severity of other functional correlates among deployed veterans (52). Berk found that those individuals who were not able to incorporate the resilience-promoting factors may have been able to cope in the short term with the immediate threat, but then had difficulties following the cessation of the armed conflict. Over the course of his subsequent visits to Bosnia, Berk found a higher rate of alcoholism and suicide among teenagers than anticipated. They had apparently survived the most imminent threat and then succumbed to long-term stress. Some of these problems were due to the demobilization from the army of those teenagers who had been in the military. They were now left with no defined role after having had an important one, which had given them considerable power. The demobilization of their fathers caused problems as well. Friction between the parents arose as the father took authority back from the mother who had been in charge of the family in the father's absence. He also found considerable turnover among humanitarian aid workers. Those who had been able to stay on the job and be effective in the long run were those who had truly internalized resilience strategies (53).

Amongst 149 male survivors from "ethnic cleansing" camps in Bosnia during 1992 who were examined within two weeks from arriving in Sweden as refugees, Björn et al. (54) found that they had an extremely traumatic background: $76 \%$ cent had a history of physical abuse, $17 \%$ had survived systematical physical torture and $89 \%$ had undergone psychic torture, but few serious somatic problems were found. The most important factor for their present well-being was if their family and other relatives had been reunited and if they knew what had happened 
to other members of their family. The authors suggested that by early identification of a high risk for developing PTSD and by focusing the general risk that everyone in the investigated group faced to develop this symptomatology, relevant contact could be established before severe symptoms developed (54).

Despite the mental health service reform performed in $\mathrm{BH}$, in the treatment of war traumatized veterans, their spouses and children today, important obstacles are still present today on both social and political levels in the organization of the health care system in postwar $\mathrm{BH}$. The stigmatization of mental health issues is an important problem in the treatment of traumatized individuals, especially among war veterans. The lack a single Center for psycho trauma in postwar $\mathrm{BH}$ shows the absence of political will in $\mathrm{BH}$ to resolve the problem of war veterans with trauma related psychological disorders (55).

\section{Poverty}

It is known that often the direct effects of war trauma tend to be more easily seen and investigated than indirect effects, such as poverty. Poverty has been described as an economic state that does not allow the provision of the family's and children's basic needs, such as adequate food, clothing, and housing. General poverty often exerts the strongest impact on children $(56,57)$, followed by school- and health-related risks. Poor children are particularly vulnerable to the effects of poverty because of the environment they live in. Investigations among the refugee camps and the population of Sarajevo shows that "life equipment" among the displaced persons was lower than in local people. That shows that after the phase of surviving, this part of the population was at risk of many psycho-social problems. Also, the very low socio-economical level of the inhabitants of Sarajevo leads to the potential of absolutely poverty. The indicators of this trend are: low level of education, very low living standard, unemployment, bad health conditions etc. Among refugees all these indicators are worse. Criminality in Sarajevo increased during the war, particularly among adolescents (5). Lack of money for essential life needs, a worse financial situation compared to the prewar period, extreme poverty, lack of income and parental unemployment increased PTSD prevalence (42). Adolescents from rural areas more frequently reported a more difficult financial situation currently than before the war, the situation of no salary in the family at all, parent(s) who lost their employment after the war, unemployed mothers, and no health insurance in comparison to their peers from urban areas. Adolescents from rural areas reported more frequent traumas due to war circumstances and more destruction of material and human resources than their peers from urban areas (42).

\section{School adjustment}

After the war, many multinational communities witnessed ethnic segregation, which was particularly visible in schools ("two schools under one roof"). In many such schools, Bosniak and Croatian children, as well as their teachers, have no mutual contact. Pupils often enter these schools through different entrances, take separate breaks, and the teachers have segregated commonrooms (41). Hasanović et al. (3) found in the research that the severity of PTSD symptoms and cluster symptoms of re-experience and avoidance were significantly reduced amongst students where the members of the School project team worked in compliance with their plan and program of psycho-social help to lessen prevailing prejudices and acceptance of differences as well as lessening aggressive features among children by 
connecting children, parents, teachers and school management in both entities, as well as the establishment of Students' clubs as a legal part of the schools in which they work. This can be explained by the fact that the war in $\mathrm{BH}$ destroyed interpersonal relationships between citizens in terms of ethnical affiliation, so the traditional trust and confidence that were cultivated amongst neighborhoods had vanished. The current school system based on ethnical school programs has differing points of view on the history of the $\mathrm{BH}$ war; the issue of who is guilty for the war increases mistrust and gaps in interethnic dialogue. This comprehensive project involved students, their teachers and school directors and particularly their parents spending a certain amount of time together, it helped them to go over the artificial and tragic ethnical division and enmity, and to reestablish trust and confidence, which help in decreasing the severity of PTSD symptoms (3). On the other hand, age, frequency of trauma experiences, PTSD, depression, hopelessness and suicidal thoughts were negatively associated with the level of the academic achievements of the study participants (40).

\section{Treatment or how to help to war traumatized children and adolescents}

The war in Bosnia was the first time the United Nations had been faced with mass rape as a weapon of war. In fact, many of the estimated 20,000 women and men who were raped or sexually abused during the war, often by gangs and often repeatedly over months, have not seen a doctor or any sort of mental health expert since. Bosnia's gynecologists in Sarajevo worked without electricity, anesthetics, or oxygen and with only a skeleton staff, to keep delivering babies at Sarajevo's University Hospital while the city was under siege. The number of pregnancies dropped dramatically, and the num- bers asking for abortions rose. Then in the late summer of 1992, some months after the war began, the women who had been raped started to appear. Most of them came alone, at night, so no one would see them. They were silent and full of shame and hatred. Often while they were treated, they would not speak. Some asked for abortions. Others gave birth and then rejected the child (53). The majority of $\mathrm{BH}$ residents were exposed to cumulative traumatic events during the 1992-1995 war, which demanded emergency organization of psychosocial support as well as psychiatric-psychological treatment of psycho-traumatized individuals (58). At the beginning of the war (1992) knowledge about the psychological consequences of war and therapeutic approaches to PTSD in $\mathrm{BH}$ was rather poor. The therapeutic approach was based on the experience of psychiatrists and their receptiveness to the ideas suggested by foreign literature and the many foreign workers $(59,60)$. At the end of the war, various psychosocial programs were organized by the government and international nongovernmental organizations $(61,62)$.

In Bosnia and Herzegovina today there are no children who experienced the war 1992-1995, because they have grown up. Some of them are still adolescents now who need our competences to help those who have mental health problems. During the war, because of the life threatening circumstances, the first task was to survive successfully. Those who stayed in $\mathrm{BH}$ in their original homes or who were internally displaced persons met the same problems; the lack of an organized structure for the mental health care of citizens and human resources adequate and competent to organize a sufficient network for mental health care in war conditions. Practically, mental health care was organized in psychiatry departments in existing $\mathrm{BH}$ clinical centers and only by a few nongovernmental organizations (NGO). The psychosocial approach to trauma aimed 
to reduce not only the risk of serious mental disorders but also stigma, through mass education about the psychological consequences of trauma. The therapy methods applied have had a significant effect in increasing children's willingness to take part in the dialogue, in increasing the interest to work in a group and a greater contribution from each one within the group. It has been confirmed that the effect of methodical procedure and therapy treatment at children is successful and applicable in future activities (63). Working with traumatized people during the war, we perceived that religious people coped more successfully with difficulties than those who were not religious. In selected cases, spirituality and religion are therefore used in the process of healing, and so they have found their place in educational programs and psychotherapeutic treatment. In hospitals, appropriate rooms were allocated for the spiritual and religious needs of patients (64).

For refugees there were some attempts made in the different countries where they were living. We have some evidence in scientific literature. Snyder et al. (65) focused on the influence of societal and cultural values coupled with wartime experiences on the transition of Bosnian refugee families to their new countries. They suggested that social workers can use culturally competent theoretical frameworks and practice principles to assist Bosnian Muslim children and families in their adaptation process within their resettlement communities (65).

Brunvatne et al. (66) stated that Bosnian "war refugees" who sought shelter in Norway after the first two years of the war in Bosnia (1992-93) had experienced extreme traumas, qualifying them for help from expert psychotherapists, but no such help was available. Most of them were former prisoners from Serbian concentration camps, together with their families. Authors investigated whether useful psychosocial preventive work could be done within the primary health services during a six month period in 1993-94. They concluded that all the refugees reported that they experienced deep sorrow, and the majority had difficulty in sleeping and concentrating. A pessimistic view of their future was common. Most of the refugees were positive towards participating in the interviews. Several of them reported that the interviews were of direct help. In the majority of cases the authors have experienced that ordinary health contacts later were meaningful (66).

After assessing war violence exposure and behavioral symptoms in 31 Bosnian refugee children in 1996 at the International Clinic of Boston Medical Center, in Massachusetts and behavioral screening of refugees during the Refugee Health Assessment (RHA), the state's largest contracted provider of the RHA, Geltman et al. (67) emphasized that children were also offered referrals to appropriate mental health services. Authors found that $68 \%$ experienced long-term separation from a parent, $81 \%$ were directly exposed to armed combat, $71 \%$ experienced the death of a close friend or relative, 52\% experienced economic deprivation. Families reported behavioral symptoms in $77 \%$ of children. Only one family expressed an interest in psychosocial services of any kind. Finally they concluded that large numbers of Bosnian refugees were likely to have experienced traumatic war violence and are at risk of behavioral symptoms, but the RHA affords opportunities to screen for behavioral problems but not intervention. Additionally they recommended that primary care providers and other clinicians should be aware of likely recurrences of symptoms in high-risk children such as these (67).

In their review article, Ehntholt and Yule (68) found that young refugees were frequently subjected to multiple traumatic events and severe losses, as well as ongoing stressors within the host country. Although 
young refugees are often resilient, many experience mental health difficulties, including PTSD, depression, anxiety and grief. They underlined that an awareness of relevant risk and protective factors is important, and that a phased model of intervention is often useful, as well as the need for a holistic approach crucial. Promising treatments for alleviating symptoms of war-related PTSD include cognitive behavioral treatment (CBT), testimonial psychotherapy, narrative exposure therapy (NET) and eye movement desensitization and reprocessing (EMDR). Knowledge of the particular needs of unaccompanied asylum-seeking children (UASC), working with interpreters, crosscultural differences, medico-legal report writing and the importance of clinician selfcare is also necessary (68).

Murray et al. (69) in their article focuses on the mental and behavioral health component of services for refugee youth, suggesting that the diverse clinical presentation of refugee children and adolescents after their traumatic experiences requires a treatment model that can mitigate a number of internalizing and externalizing symptoms. Refugee populations also require interventions that can adjust to the wide-ranging experiences likely encountered during preflight, flight, and resettlement. There is some evidence that immigration stressors or social stressors, such as discrimination, are associated with symptoms of posttraumatic stress disorder in refugee youth. Therefore refugee youth may benefit from multiple levels of services ideally integrated (69).

After a year's experience (from August 1997 until July 1998) of being psychotherapist supervisor and trainer in Bosnia, Wintsch (70) declared that even though it was sometimes really difficult, looking back it seems to him that it was a very meaningful and helpful work in the service of children and adults in order to provide new hope and to help them to cope with their war trauma.
As he had really good results, he wanted to encourage other psychotherapists and psychiatrists to dare to contribute their skills in similar work. He emphasized all general conditions and the need for building up sufficient therapeutic and training project conditions with local partners in a poor, neglected and remote area, to build up trust; work on trauma; training for local professionals; results, evaluation and continuation of eventual project(s) (70).

\section{Conclusion}

The young $\mathrm{BH}$ population who survived the 1992-1995 war is a multi-traumatized group. Traumatic symptoms are related to harm avoidant personality traits. Certain war experiences were also associated with greater symptomatology. The findings show that there may be more serious longer-term psychological problems in young people who were forced to leave their property, original homes and country during wartime, and who lost fathers and/or other family members. There were regional variations in warfare. The most difficult war trauma was in surviving children and adolescents from Sarajevo and Srebrenica. The adolescents examined revealed a variety of serious psychological manifestations, including PTSD, depression, suicidal thoughts, somatic and behavioral problems, that influenced their academic achievements. Children who had fled their homes together or without complete families were likely to have had particularly harsh war experiences, which were additionally complicated by the processes of acculturation and repatriation and lack of basic means for life. The wide spread the fighting and the large numbers of families displaced by the war suggests that the findings from these studies are likely to reflect the experience of a large proportion of the young Bosnian population. This might be considered as a general characteristic of a 
society in war. The treatment of war-traumatized children and adolescents was rare, insufficient and of differing characteristics, depending on where the children and adolescents were settled after surviving trauma, in their homeland or in a foreign country. In the organizing of the health care system in postwar $\mathrm{BH}$, meaningful obstacles are still present today on both the social and political levels, despite the mental health service reform performed in $\mathrm{BH}$. The stigmatization of mental health issues is an important problem in the treatment of traumatized individuals, especially among war veterans, their spouses and children. The lack of a single Center for psycho trauma in postwar $\mathrm{BH}$ shows the absence of political will in $\mathrm{BH}$ to resolve the problem of war veterans with trauma related psychological disorders. Psychosocial work with elementary and secondary school students, giving them psychosocial support within the School Project resulted in a significant reduction of PTSD symptom severity. More research is required to expand our limited knowledge base and improve our understanding of disorder prevalence, as well as associated information on course, phenomenology. More research is also needed to delineate the factors that reflect a risk for PTSD after trauma, factors that reflect the consequences of PTSD, and mediating variables. Future studies in this area would benefit from a prospective design, the evaluation of possible protective processes (e.g. social support), and specific examination of particular aspects of resilience and how resilience may be increased. This may help in establishing a network of resources for adequate treatment, and decreased economic costs.

\section{Acknowledgements}

I would like to express my thanks to children, adolescents, their parents, school authorities, teachers, school pedagogues-psychologists, psychiatrists, mental health worker and researchers and many other individuals from all the world for their contribution in helping $\mathrm{BH}$ people in very dangerous war period and in the post-period until the present day. I would like to express my particular thanks to donors who have helped in the reconstruction of devastated houses and schools, which has helped the return to a more normal living environment in postwar $\mathrm{BH}$.

Conflict of interest: The author declares he has no conflict of interest. This study was not sponsored by any external organization.

\section{References}

1. Smith P, Perrin S, Yule W, Rabe-Hesketh S. War exposure and maternal reactions in the psychological adjustment of children from Bosnia-Hercegovina. J Child Psychol Psychiatry. 2001;42(3):395-404.

2. Hasanović $M$, Sinanović $O$, Selimbašić Z, Pajević I, Avdibegović E. Psychological Disturbances of War-traumatized Children from Different Foster and Family Settings in Bosnia and Herzegovina. Croat Med J. 2006;47(1):85-94.

3. Hasanović M, Srabović S, Rasidović M, Sehović M, Hasanbasić E, Husanović J, Hodzić R. Psychosocial assistance to students with posttraumatic stress disorder in primary and secondary schools in post-war Bosnia Herzegovina. Psychiatr Danub. 2009;21(4):463-73.

4. Hasanovic M, Sinanovic O, Pavlovic S. Acculturation and psychological problems of adolescents from Bosnia and Herzegovina during exile and repatriation. Croat Med J. 2005;46:105-15.

5. Loga S, Cerić I, Stojak R, Kantardzić D, Danes V, Trograncić Z, Fiseković S, Stanić D, Termiz D, Kulenović F, Licanin I, Papović S, Resić D. Psychosocial research during the war in Sarajevo. Med Arh. 1999;53(3):139-44.

6. Goldstein RD, Wampler NS, Wise PH. War experiences and distress symptoms of Bosnian children. Pediatrics. 1997;100(5):873-8.

7. Bull D. Operation joint forge veterans - Balkan tour broadens scope. Vet. Center Voice. 2004;25(4):12-16.

8. Weinberg J, Simmonds S. Public health, epidemiology and war. Soc Sci Med. 1995;40:1663.

9. Jensen PS, Shaw J. Children as victims of war: current knowledge and future research needs. J Am Acad Child Adolesc Psychiatry. 1993;32:697-708.

10. Papageorgiou V, Frangou-Garunovic A, Iordanidou R, Yule W, Smith P, Vostanis P. War trauma and psychopathology in Bosnian refugee children. Eur Child Adolesc Psychiatry. 2000;9:84-90.

11. Husain SA, Nair J, Holcomb W, Reid JC, Vargas V, Nair SS. Stress reactions of children and adoles- 
cents in war and siege conditions. Am J Psychiatry. 1998;155:1718-9.

12. Rutter M. Maternal deprivation reassessed. 2nd ed. London: Penguin Books; 1991. p. 19.

13. Röper G, Gavranidou M. Capacity building in trauma therapy and trauma research in Bosnia-Herzegovina. New Dir Youth Dev, 2003;(98):99-110.

14. Hasanović M, Pavlović S, Sinanović O. Acculturation and Psychological Characteristics of Bosnian Internally Displaced and Refugee Adolescents from Srebrenica Region after the War 1992-1995 in Bosnia and Herzegovina. In: Rene S. Grenell (ed.) Adolescent Behavior Research Studies. New York: Nova Publishers; 2007 - 3rd Quarter. p. 155-91.

15. Lonigan CJ, Philips BM, Richey JA. Posttraumatic stress disorder in children: diagnosis, assessment, and associated features. Child Adolesc Psychiatr Clin N Am. 2003;12(2):171-94.

16. Jones L, Kafetsios K. Assessing adolescent mental health in war-affected societies: the significance of symptoms. Child Abuse Negl. 2002;26(10):1059-80.

17. Goldin S, Levin L, Persson LA, Hägglof B. Stories of pre-war, war and exile: Bosnian refugee children in Sweden. Med Confl Surviv. 2001;17(1):25-47.

18. Alwood MA, Bell-Dolan D, Husain SA. Children's trauma and adjustment reactions to violent and nonviolent war experiences. J Am Acad Child Adolesc Psychiatry. 2002;41(4):450-7.

19. Allden K, Cerić I, Kapetanović A, Lavelle J, Loga S, Mathias M, \& McInnes K. Merhamet Medical Team-Rijeka, Mollica RF, Puratić V, Ruke TeamZagreb, Sarajlić N (alphabetical order). Harvard Trauma Manual: Bosnia-Herzegovina Version. Cambridge (MA): Harvard Program in Refugee Trauma; 1998. (Available in English and Bosnian).

20. Allden K, Frančišković T, Lavelle J, Mathias M, McInnes K, Mollica RF \& Moro L. (alphabetical order). Harvard Trauma Manual: Bosnia-Herzegovina Version. Cambridge (MA): Harvard Program in Refugee Trauma; 1998. (Available in English and Bosnian).

21. Goldin S, Levin L, Persson LA, Hägglof B. Child war trauma: a comparison of clinician, parent and child assessments. Nord J Psychiatry. 2003;57(3):173-83.

22. Angel B, Hjern A, Ingleby D. Effects of war and organized violence on children: a study of Bosnian refugees in Sweden. Am J Ortopsychiatry. 2001;71(1):4-15.

23. Horowitz MJ, Wilner N, Alvarez W. Imact of Event Scale: a measure of subjective stress. Psychosom Med. 1979;41:209-18.

24. Brennen T, Hasanović M, Zotović M, Blix I, Skar AM, Prelić NK, Mehmedović I, Pajević I, Popović
N, Gavrilov-Jerković V. Trauma exposure in childhood impairs the ability to recall specific autobiographical memories in late adolescence. J Trauma Stress. 2010;23(2):240-7.

25. Dyregrov A, Kuterovac G, Barath A. Factor analysis of the impact of event scale with children in war. Scand J Psychol. 1996;37(4):339-50.

26. Connelly C. The new siege of Sarajevo. The Times. 2005 Oct 8.

27. Strange H. Serb general Dragomir Milosevic convicted over Sarajevo siege. The Times. 2007 Dec 12.

28. Bassiouni C. Final report of the United Nations Commission of Experts established pursuant to Security Council resolution 780. United Nations. 1994 May 27.

29. Duraković-Belko E, Kulenović A, Dapić R. Determinants of posttraumatic adjustment in adolescents from Sarajevo who experienced war. J Clin Psychol. 2003;59(1):27-40.

30. Daneš V, Horvat V. Psychological consequences of war stress in the developing population in Bosnia and Herzegovina. Psychiatr Danub. 2005;17(3-4):225-9.

31. Tahirović FH, Tulumović T, Uzeirbegović M, Hadžibegić N, Hasanović A. How war disrupts iodine prophylaxis: An example from Bosnia. IDD Newsletter. 1995:13.

32. Uvin P, Cohen MJ, Snyder AC, Hoehn RA, Harris M. Overview of world hunger. Causes of hunger. Fifth annual report on the state of world hunger. Bread for the World Institure; 1994. p. 10-20.

33. Tahirović $\mathrm{H}$. The influence of abuse and terrorism on somatic growth of children. Arabisches Arzteblatt. 1996:56-9.

34. Hay A. Surviving the impossible: the long march from Srebrenica. An investigation of the possible use of chemical warfare agents. Med Confl Surviv. 1998;14(2):120-55.

35. Pavlović D, Bijedić S. Personal experience in the organization of mass admission of traumatized refugees. Med Arh. 1997;51(1-2 Suppl 1):21-2.

36. Hasanović M, Pavlović S, Sinanović O. (2008) Acculturation and Psychological Characteristics of Bosnian Internally Displaced and Refugee Adolescents from Srebrenica Region after the War 1992-1995 in Bosnia and Herzegovina. In: Monica K. Zimmermann (ed.) Political Refugees: Social Conditions, Health and Psychological Characteristics. New York: Nova Publishers; 2008 - 3rd Quarter. p. 139-75.

37. Tahirovič FH. Menarchal age and the stress of war: an example from Bosnia. Eur J Pediatr. 1998;157:978-80.

38. Smith P, Perrin S, Yule W, Hacam B, Stuvland R. War exposure among children from Bosnia-Her- 
cegovina: psychological adjustment in a community sample. J Trauma Stress. 2002;15(2):147-56.

39. Eytan A, Gex-Fabry M, Toscani L, Deroo L, Lou$\tan$ L, Bovier PA. Determinants of postconflict symptoms in Albanian Kosovars. J Nerv Ment Dis. 2004;192(10):664-71.

40. Hasanović M, Haračić E, Ahmetspahić Š, Kurtović S, Haračić H. Poverty and Psychological Disturbances of War-Traumatized Adolescents from $\mathrm{Ru}$ ral and Urban Areas in Bosnia and Herzegovina. In: Fiedler A, Kuester I (Eds) Child Development and Child Poverty. New York: Nova Publishers; 2010. p. 229-55.

41. Cerni Obrdalj E, Rumboldt M. Bullying among school children in postwar Bosnia and Herzegovina: cross-sectional study. Croat Med J. 2008;49(4):528-35.

42. Kerestes G. Children's aggressive and prosocial behavior in relation to war exposure: testing the role of perceived parenting and child's gender. Int J Behav Dev. 2006;30: 227-39.

43. Zalihić A, Zalihić D, Pivić G. Influence of posttraumatic stress disorder of the fathers on other family members. Bosn J Basic Med Sci. 2008;8(1):20-6.

44. Monson CM, Taft CT, Fredman SJ. Military-related PTSD and intimate relationships: from description to theory-driven research and intervention development. Clin Psychol Rev. 2009;29(8): 707-14.

45. Beardslee WR, Gladstone TR, Wright EJ, Cooper AB. A family-based approach to the prevention of depressive symptoms in children at risk: evidence of parental and child change. Pediatrics. 2003;112:119-31.

46. Dahl S, Mutapcic A, Schei B. Traumatic events and predictive factors for posttraumatic symptoms in displaced Bosnian women in a war zone. J Trauma Stress. 1998;11(1):137-45.

47. Selimbasic Z, Sinanovic O, Avdibegovic E, Kravic N. Contact network and satisfaction with contacts in children whose parents have post traumatic stress disorder. Med Arh. 2009;63(3):124-7.

48. Selimbasić Z, Avdibegović E, Sinanović O. Posttraumatic stress reaction in children. Med Arh. 2000;54(3):177-80.

49. McFarlane AC. Military deployment: the impact on children and family adjustment and the need for care. Curr Opin Psychiatry. 2009;22(4):369-73.

50. Smith P, Perrin S, Yule W, Rabe-Hesketh S. War exposure and maternal reactions in the psychological adjustment of children from Bosnia-Hercegovina. J Child Psychol Psychiatry. 2001;42(3):395-404.

51. Richardson LK, Frueh BC, Acierno R. Prevalence estimates of combat-related post-traumatic stress disorder: critical review. Aust N Z J Psychiatry. 2010;44(1):4-19.

52. Green KT, Calhoun PS, Dennis MF. Mid-Atlantic Mental Illness Research, Education and Clinical Center Workgroup, Beckham JC. Exploration of the resilience construct in posttraumatic stress disorder severity and functional correlates in military combat veterans who have served since September 11, 2001. J Clin Psychiatry. 2010;71(7): 823-30.

53. Berk JH. Trauma and resilience during war: a look at the children and humanitarian aid workers of Bosnia. Psychoanal Rev. 1998;85(4):640-58.

54. Björn A, Eriksson T. Released Bosnian prisoners of war. High risk of posttraumatic symptoms. Lakartidningen. 1993;90(24):2305-8.

55. Arie S. Conflict and Rape. After war, what next? BMJ. 2010;341:c6910.

56. Cairns E, Dawes A. Children: Ethnic and political violence - A commentary. Child Development. 1996;67:29-139.

57. Dybdahl R. Children and mothers in war: An outcome Study of a psychosocial intervention program. Child Development. 2001;72(4),1214-30.

58. Avdibegović E, Hasanović M, Selimbasić Z, Pajević I, Sinanović O. Mental health care of psychotraumatized persons in post-war Bosnia and Herzegovina--experiences from Tuzla Canton. Psychiatr Danub. 2008;20(4):474-84.

59. Sinanović O, Avdibegović E, Hasanović M, Pajević I, Sutović A, Loga S, Cerić I. The organisation of mental health services in post-war Bosnia and Herzegovina. International Psychiatry. 2009;6(1):10-12.

60. Hasanović M, Sinanović O, Pajević I, Avdibegović E, Sutović A. (2006) Post-war mental health promotion in Bosnia-Herzegovina. Psychiatria Danubina. 18(1-2):74-78.

61. de Jong K \& Stickers R. Early psychosocial interventions for war-affected populations. In: Orner $\mathrm{R}$ \& Schnyder U (eds). Early interventions in emergencies. Oxford University Press; 2003.

62. Nelson BS. Post war trauma and reconciliation in Bosnia and Herzegovina: observations, experiences, and implications for marriage and family therapy. Am J Fam There. 2003;31(4):305-316.

63. Selimbasić Z, Pavlović S, Sinanović O, Vesnić S, Petrović M, Ferković V, Cipurković-Mustacević A. Posttraumatic stress disorder--effects of psychosocial treatment in children. Med Arh. 2001;55(1 Suppl 1):25-9.

64. Pajević I, Sinanović O, Hasanović M. Religiosity and mental health. Psychiatria Danubina. 2005;17(1-2):84-9. 
65. Snyder CS, May JD, Zulcic NN, Gabbard WJ. Social work with Bosnian Muslim refugee children and families: a review of the literature. Child Welfare. 2005;84(5):607-30.

66. Brunvatne R, Lysgård KH, Hjortdahl P. Psychosocial preventive work among war refugees. A task for primary health care? Tidsskr Nor Laegeforen. 1995;115(1):23-6.

67. Geltman PL, Augustyn M, Barnett ED, Klass $\mathrm{PE}$, Groves BM. War trauma experience and behavioral screening of Bosnian refugee children resettled in Massachusetts. J Dev Behav Pediatr. 2000;21(4):255-61.
68. Ehntholt KA, Yule W. Practitioner review: assessment and treatment of refugee children and adolescents who have experienced war-related trauma. Journal of Child Psychology and Psychiatry. 2006;47(12):1197-210.

69. Murray LK, Cohen JA, Ellis BH, Mannarino A. Cognitive behavioral therapy for symptoms of trauma and traumatic grief in refugee youth. Child Adolesc Psychiatr Clin N Am. 2008;17(3):585-604.

70. Wintsch H. Spreading hope: therapeutic teams with war-traumatized children and adolescents in Bosnia. Prax Kinderpsychol Kinderpsychiatr. 2000;49(3):209-30. 